\title{
Effect of waxy (Low Amylose) on Fungal Infection of Sorghum Grain
}

\author{
Deanna L. Funnell-Harris, Scott E. Sattler, Patrick M. O’Neill, Kent M. Eskridge, and Jeffrey F. Pedersen
}

First and third authors: Grain, Forage and Bioenergy Research Unit (GFBRU), U.S. Department of Agriculture-Agricultural Research Service (USDA-ARS), and Department of Plant Pathology, University of Nebraska, Lincoln, NE 68583-0937; second and fifth authors: GFBRU, USDA-ARS, Department of Agronomy and Horticulture, University of Nebraska, Lincoln, NE 68583-0937; and fourth author: Department of Statistics, University of Nebraska, Lincoln, NE 68583-0937.

Accepted for publication 23 January 2015.

\begin{abstract}
Funnell-Harris, D. L., Sattler, S. E., O’Neill, P. M., Eskridge, K. M., and Pedersen, J. F. 2015. Effect of waxy (low amylose) on fungal infection of sorghum grain. Phytopathology 105:786-796.

Loss of function mutations in waxy, encoding granule bound starch synthase (GBSS) that synthesizes amylose, results in starch granules containing mostly amylopectin. Low amylose grain with altered starch properties has increased usability for feed, food, and grain-based ethanol. In sorghum, two classes of waxy $(w x)$ alleles had been characterized for absence or presence of GBSS: $w x^{a}\left(\mathrm{GBSS}^{-}\right)$and $w x^{b}\left(\mathrm{GBSS}^{+}\right.$, with reduced activity). Field-grown grain of wild-type; waxy, GBSS ${ }^{-}$; and waxy, GBSS ${ }^{+}$ plant introduction accessions were screened for fungal infection. Overall,

results showed that waxy grains were not more susceptible than wild-type. GBSS $^{-}$and wild-type grain had similar infection levels. However, height was a factor with waxy, GBSS ${ }^{+}$lines: short accessions $\left(w x^{b}\right.$ allele) were more susceptible than tall accessions (undescribed allele). In greenhouse experiments, grain from accessions and near-isogenic $w x^{a}, w x^{b}$, and wildtype lines were inoculated with Alternaria sp., Fusarium thapsinum, and Curvularia sorghina to analyze germination and seedling fitness. As a group, waxy lines were not more susceptible to these pathogens than wildtype, supporting field evaluations. After C. sorghina and F. thapsinum inoculations most waxy and wild-type lines had reduced emergence, survival, and seedling weights. These results are valuable for developing waxy hybrids with resistance to grain-infecting fungi.
\end{abstract}

Numerous waxy mutants, identified in sorghum (Sorghum bicolor (L.) Moench), millets, barley (Hordeum vulgare L.), wheat (Triticum spp.), rice (Oryza sativa L.), and maize (Zea mays L.), reduce the amylose content of the starch $(11,12,19,20,65,72)$. In wild-type plants, amylose makes up approximately one-fourth of starch and amylopectin encompasses the remaining portion. Having greatly reduced to undetectable amounts of amylose, waxy can increase usability of the grain for animal feeds and some food products $(10,11,34,46,64)$. The waxy trait results from loss of function mutations in the waxy gene(s) responsible for granule bound starch synthase (GBSS), critical for amylose production (56). Recently, waxy sorghum and corn have gained attention for possible use in ethanol production in the bioenergy industry $(26,73)$. Greater fermentation efficiencies have been reported with waxy grains because amylose forms lipid complexes that are resistant to enzymatic hydrolysis, and greater swelling and fragmentation of starch granules during heating has been reported with waxy grain $(56,73,76)$. Waxy starch also has lower pasting temperature, reducing energy demands during ethanol production (76).

In sorghum, wild-type grain contains 22 to $24 \%$ amylose and waxy grain contains $2 \%$ or less amylose $(49,53)$. A previous study identified two types of waxy mutants, based on the presence or absence of the GBSS protein, designated $w x^{a}$ and $w x^{b}$, respectively $(49,56)$. Further characterization revealed that $w x^{b}$ had a missense mutation that affected a highly conserved amino acid in GBSS, resulting in only partial function (56). Further characterization of $w x^{a}$ showed that the gene contained a large insertion, which likely

Corresponding author: D. Funnell-Harris;

E-mail address: Deanna.Funnell-Harris@ars.usda.gov

*The $e$-Xtra logo stands for "electronic extra" and indicates that five supplementary tables are published online.

http://dx.doi.org/10.1094/PHYTO-09-14-0255-R

This article is in the public domain and not copyrightable. It may be freely reprinted with customary crediting of the source. The American Phytopathological Society, 2015. prevented the accumulation of GBSS protein. At least two more $w x$ alleles were identified by screening diverse sorghum germplasm $(24,38)$, using DNA markers developed for the $w x^{a}$ and $w x^{b}$ alleles (56).

Despite interest in waxy grain, published reports specifically examining effects of waxy on response to grain pathogens are limited. In a study of aflatoxin contamination (correlated with Aspergillus flavus Link. infection [7]) in kernels of maize hybrids with differing endosperm characteristics, a waxy hybrid had significantly greater mean aflatoxin levels than its wild-type counterpart (35). Other modifications of the endosperm may also indirectly affect amylose content of grains. For example, the Opaque-2 (O2) gene encodes a transcriptional activator, specifically expressed in maize endosperm. o2 mutants have greatly reduced amounts of the endosperm protein zein (60) and somewhat reduced amylose content (28 to $29 \%$ compared with 32 to $34 \%$ in wild-type) (21); $o 2$ lines are known to be susceptible to pathogens (37). Due to the pleotropic effects of the mutation, including increased softness, also associated with disease susceptibility $(22,70)$, it is difficult to ascertain the factors involved in these observations. These few studies illustrate the necessity of a thorough investigation to determine whether waxy sorghum is more susceptible than wild-type to grain pathogens.

There is evidence that impaired GBSS activity alters the structure of the grain. Scanning electron microscopy (SEM) revealed differences in endosperm appearance between wild-type and waxy grain (56). Wild-type grains had a floury-appearing endosperm in the center of the grain, surrounded by the vitreous (slightly translucent) region, while waxy grains had a smaller floury endosperm region surrounding the embryo while the vitreous region was found in the middle of the grain (56). The vitreous region of waxy grains was more loosely packed than that of wild-type grains (56). Physicochemical properties of the starch from wildtype and waxy grains are also different. GBSS, as the name implies, is primarily associated with starch granules; the granules in waxy grains are made up almost entirely of amylopectin, and $w x^{a}$ 
sorghum genotypes, do not have GBSS (49). $w x^{b}$ genotypes do include the low activity GBSS bound in the starch granules (49). Other proteins in sorghum endosperm include the major storage proteins, kafirins, similar to maize zeins (72). Kafirins form protein bodies, which are held together by other proteins, making a matrix that surrounds starch granules. In endosperm of a wild-type line, the protein bodies were shown to be more closely associated with starch granules, as compared with that of a closely related waxy line (72). Other differences between waxy and wild-type grains include starch thermal properties, mean gelatinization temperatures being significantly higher in waxy lines than wild-type (50), and increased digestibility of proteins in waxy grains (72).

In addition to grain proteins just described, there are those implicated in resistance to grain fungal infections. Although little is known about these antifungal proteins in waxy grain, much research has been conducted with wild-type grain. Several proteins (sormatin, a thaumatin-like protein; a $\beta$-1,3-glucanase; chitinases; and a ribosomalinactivating protein) from sorghum grain that strongly inhibit in vitro fungal growth have been found (62). These proteins are present in the grain throughout development $(29,51,52,61)$, including when the immature grain is most vulnerable to fungal attack $(39,44)$. Additionally, sormatin and chitinase have been shown to be inducible or retained under high grain mold pressure $(51,52)$. Thus, changes to endosperm structure, including how the protein matrix interacts with starch granules, the composition of starch granules, and increased protein digestibility observed in waxy grain $(23,56,72)$, may alter its interactions with fungi relative to wild-type grains.

Grain mold is a destructive disease of sorghum, reducing yield and quality $(44,69)$. A complex of fungi infecting flowers at anthesis, or developing grain, causes this disease. Because of the complexity of the disease, resistance is a polygenic trait, influenced strongly by environment $(2,3,63)$. In sorghum, numerous species have been implicated in grain mold but most commonly detected are species of Fusarium, Cochliobolus, and Alternaria $(5,39,71)$. Some Fusarium and Alternaria species produce mycotoxigenic compounds that cause serious diseases in both humans and livestock $(33,36,58)$. These fungi cause grain deterioration in the field or during storage, and therefore, represent a threat for sorghum produced for feed, food, and fuel $(9,57)$.

In the present study, field grown grain from photoperiod insensitive plant introductions (PIs), were screened for the presence of grain mold fungi. Additionally, grain from a subset of the PIs and near-isogenic $w x^{a}$ and $w x^{b}$ lines were inoculated with grain mold fungi. In this way, the following hypothesis was tested: waxy grain is not more susceptible to the grain mold pathogens Alternaria, Fusarium, and Cochliobolus spp. than wild-type grain.

\section{MATERIALS AND METHODS}

Fungi and media. Fungi utilized in this study were Alternaria sp. isolate H02-781S-3b, Gibberella thapsina Klittich, J.F. Leslie, P.E. Nelson \& Marasas isolate H03-11S-9, and Curvularia sorghina R.G. Shivas \& Sivan. 1987 isolate H05-531S-2 (13,14,16). The three were isolated from sorghum grain grown at the University of Nebraska Havelock field in Lincoln. For ease and familiarity to the reader, G. thapsina will be referred to as Fusarium thapsinum. Working cultures of the fungi were maintained on one-half strength potato dextrose agar (PDA), prepared using potato dextrose broth (Becton, Dickinson and Co. [BD], Sparks, MD), with $100 \mu \mathrm{m}$ ampicillin (Sigma-Aldrich [SA], St. Louis). For sporulation cultures, $F$. thapinum cultures were transferred to $80 \mathrm{mM}$ potassium chloride/1.5\% agar $(\mathrm{KCl})$, as previously described (16) and grown at room temperature for 10 days. For sporulation of Alternaria sp., transfers were made to $2 \%$ water agar with sterile filter paper $\left(1 \mathrm{~cm}^{2}\right)$ aseptically placed over the inoculation site and then grown at room temperature for 10 days. Sporulation of $C$. sorghina was also accomplished using water agar, except cultures were incubated at $22^{\circ} \mathrm{C}$ with $8 \mathrm{~h}$ light for 10 days.
For isolation of fungi from grain, the semiselective media used were dichloran rose bengal chloramphenicol (DRBC) agar, dichloran chloramphenicol peptone agar (DCPA) and pentchloronitrobenzene (PCNB) agar $(1,27,43)$. DRBC is a general purpose fungal medium that contains rose bengal, a stain that suppresses bacterial growth and slows growth of rapidly-growing fungi. DCPA is semiselective for Fusarium spp., and Alternaria spp. and other dark-spored ascomycetes. PCNB is semiselective for Fusarium spp. Dichloran, rose bengal and chloramphenicol were from SA, pentachloronitrobenzene, formulated as Terrachlor, was from Uniroyal Co. (Middlebury, CT), and agar and peptone, under the name Bacto, were from BD.

Plant lines. Information about the sorghum PIs, the known waxy line, 'Ellis', and nine wild-type lines, 'Atlas', 'Brawley', 'Dale', E35-1, IS2261, 'Kansas Collier', N98, 'Rox Orange', and 'Wray', is provided in Table 1. The PIs were obtained from the USDA-ARS Southern Regional Plant Introduction Station, Griffin, GA. There are no known previous reports of responses to grain mold fungi for any of these lines (http://www.ars-grin.gov/npgs/). Waxy phenotypes and presence $(+)$ or absence $(-)$ of GBSS were previously determined (49,50). All lines listed in Table 1 were utilized in the field study, and those lines marked with asterisks were chosen for use in a greenhouse seed inoculation study. In separate greenhouse studies, grain from the $\mathrm{S} 7$ generation of 11 pairs of near-isogenic waxy lines and corresponding wild-type lines, released May 2014 (75), an unreleased pair ([F2 BTx2752 ms3 × B 94C274])/B94C274 BC1), along with wild-type lines RTx430 and Wheatland, were inoculated (Table 2). Grain from the S6 generation of three waxy near-isogenic pairs containing either $w x^{a}\left(\mathrm{GBSS}^{-}\right)$or $w x^{b}\left(\mathrm{GBSS}^{+}\right)$allele, $($ BTxAGR1 $\times$ [BTx630 $\times$ BTxAGR1] BC1), the parental lines BTx630 $\left(w x^{a}\right)$ and BTxAGR1 $\left(w x^{b}\right)$, and the wild-type lines BWheatland and RTx430, were also inoculated. For greenhouse studies, grain produced in the greenhouse was utilized. Grain for PIs was grown in 2004, 2006, 2010, and 2012, grain for the near-isogenic $w x^{a}$ and $w x^{b}$ and corresponding wild-type lines was grown in 2009, and grain for $w x^{a}$ and $w x^{b}$ near-isogenic lines was grown in 2008 and 2009. Our previous studies have shown that greenhouse-grown sorghum grain has very low levels of endophytic fungi (less than $0.2 \%)(15)$

DNA marker analyses and iodine staining of $\mathrm{GBSS}^{+}$and GBSS- waxy PIs. To determine whether lines with $\mathrm{GBSS}^{-}$or $\mathrm{GBSS}^{+}$waxy phenotypes, previously characterized (49), had $w x^{a}$ or $w x^{b}$ alleles, respectively, markers for these alleles were utilized (56). DNA from waxy PIs and the control lines BWheatland (wildtype), RTx2901 ( $\left.w x^{a}\right)$ and BTxAGR1 $\left(w x^{b}\right)$ were screened for the $w x^{a}$ or $w x^{b}$ allele as previously described (56). DNA was extracted using the "paint shaker" method (55), modified as follows. Metal beads with $40 \mu \mathrm{l}$ of $10 \mathrm{mM}$ Tris, $\mathrm{pH} 8.0,1 \mathrm{mM}$ EDTA (TE) were used to disrupt tissue and then, after shaking, the mixtures were briefly centrifuged at room temperature. Extraction buffer $(60 \mu \mathrm{l}$ of a solution of $2 \%$ cetyl trimethylammonium bromide, $1.42 \mathrm{M}$ sodium chloride, $20 \mathrm{mM}$ EDTA, $100 \mathrm{mM}$ Tris, $\mathrm{pH} \mathrm{8.0,2 \%}$ polyvinylpolypyrrolidone, and $5 \mathrm{mM}$ ascorbic acid) and $1 \mu \mathrm{l}$ of RNase A were added and mixtures were shaken by hand, following room temperature incubation for $15 \mathrm{~min}$ and then briefly centrifuged. Chloroform/isoamyl alcohol (24:1) $(75 \mu \mathrm{l})$ was added and the mixtures were mixed by hand and then centrifuged at room temperature for $15 \mathrm{~min}$. The supernatant was collected and DNA from six plants of each cultivar was pooled. DNA was precipitated with isopropanol $(\times 0.7)$ and incubated for at least $1 \mathrm{~h}$ at $4^{\circ} \mathrm{C}$ and then centrifuged at maximum speed, $4^{\circ} \mathrm{C}$, for $15 \mathrm{~min}$. The resulting pellet was washed, dried, and resuspended in $50 \mu \mathrm{l}$ of TE. PIs previously listed as $w x^{a}$ were screened with the allele specific multiplex primer set and those previously listed as $w x^{b}$ were screened using a cleavage amplified polymorphic sequence (CAPS) marker that distinguishes $W x$ from $w x^{b}$ (56). DNA from PI 23231, PI 217897, and PI 548008 were tested with both markers. The polymerase used was AmpliTaq Gold (Life Technologies, Grand Island, NY) and HF NcoI was 
purchased from New England Biolabs, Ipswich, MA. Grain from PI 23231, PI 217897, and PI 548008, along with BWheatland (wildtype) and 94C289 (waxy), was stained with iodine to determine presence or absence (waxy phenotype) of amylose, as previously described $(48,50)$. Chemicals were purchased from Sigma Chemical Co., St. Louis, and Fisher Scientific, Waltham, MA.

Field study. The PIs, Ellis (waxy), and nine wild-type lines were planted in a randomized complete block (RBC) design with four replications each year, during 2004 and 2005, at the University of
Nebraska, Agricultural Research and Development Center near Mead, NE. In a previously published study (17), planted near the present study in the same field, disease pressure for grain infections was significantly less in 2004 than in $2005(P=0.01)$. Plots consisted of single 7.6-m rows spaced $76 \mathrm{~cm}$ apart. Grain was sown on 21 May 2004 and on 23 May 2005. Details of field management for 2004 were previously described (50). In 2005, nitrogen fertilizer was applied at $157 \mathrm{~kg} \mathrm{ha}^{-1}$ before planting. Atrazine was applied at $2.2 \mathrm{~kg} \mathrm{ha}^{-1}$ immediately after planting, followed by an application

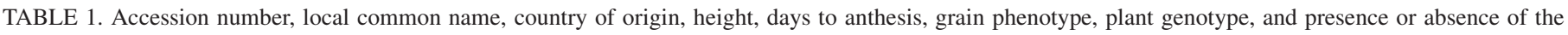
granule bound starch synthase protein (GBSS) in starch granules, of plant introductions (PIs) and other lines used in this study

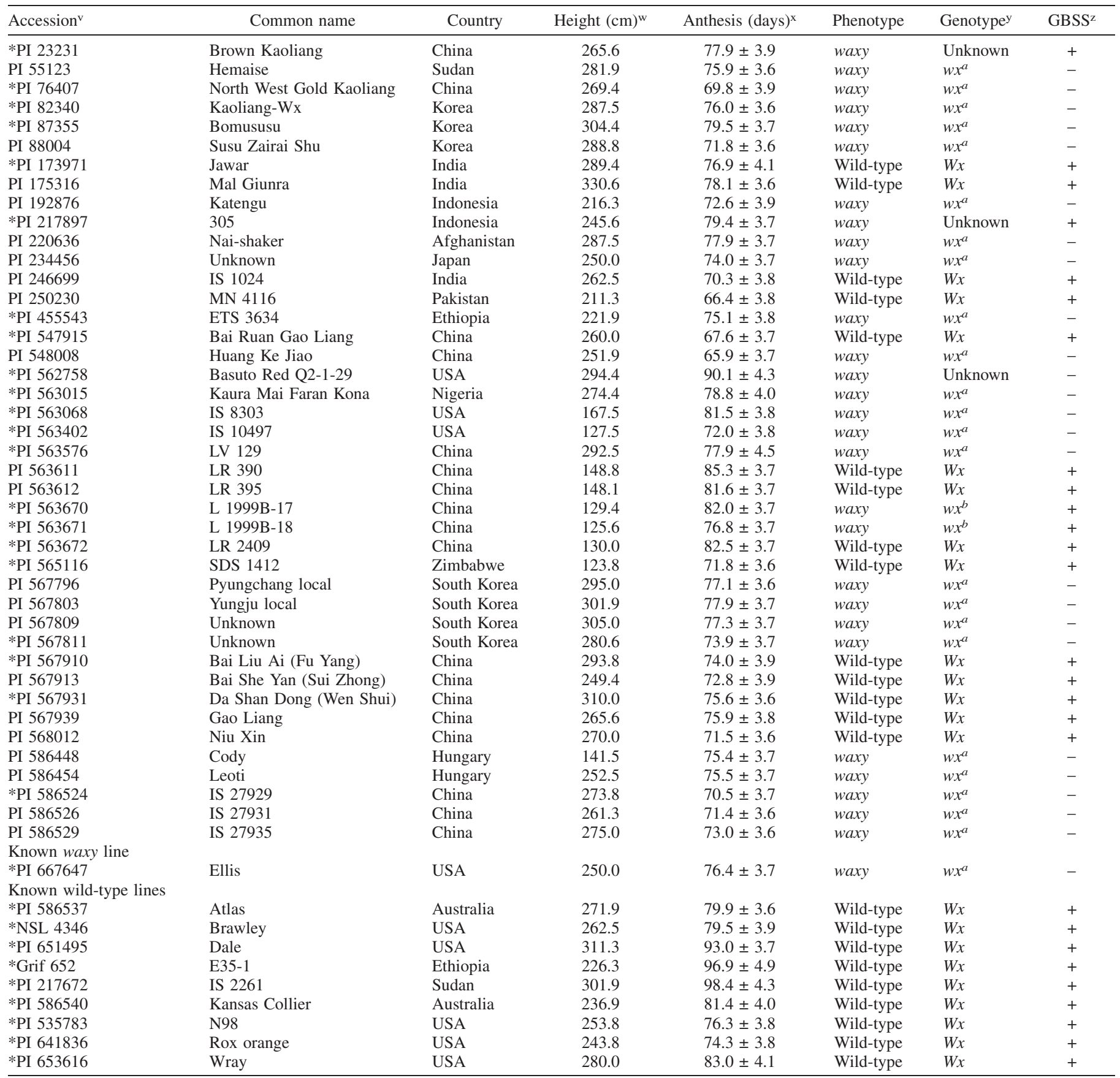

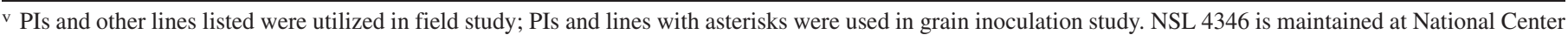
for Genetic Resources Preservation, Fort Collins, CO, while all others are maintained at the Plant Genetic Resources Conservation Unit, Griffin, GA.

w Average plant height was estimated when the plants in a plot reached anthesis (defined below). Plot measurements were rounded to the nearest $5 \mathrm{~cm}$.

${ }^{x}$ Days to anthesis was determined when the anthers from half the plants in a plot were exerted.

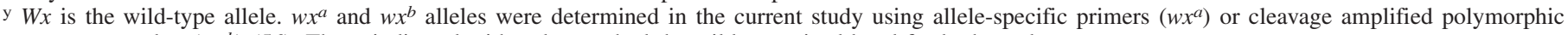
sequence marker $\left(w x^{b}\right)(56)$. Those indicated with unknown had the wild-type-sized band for both markers.

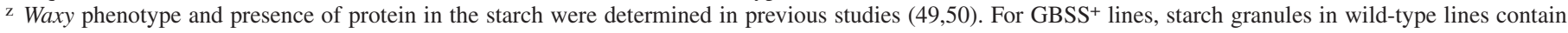
functional GBSS and waxy lines have partially active GBSS. GBSS ${ }^{-}$lines lack the protein in starch granules. 
of alachlor (2-chloro-2',6'-diethyl- $N$-[methoxymethyl] acetanilide) at 4.75 liters $\mathrm{ha}^{-1}$ and atrazine at $1.1 \mathrm{~kg} \mathrm{ha}^{-1}$, approximately 14 days postemergence. Supplemental irrigation $(3.8 \mathrm{~cm})$ was applied on 25 May, 28 June, 28 July, 4 August, and 11 August.

In both years, five grain heads were randomly chosen from each plot and the threshed grain from all five heads was pooled, dried at room temperature, and stored in a cold room $\left(4^{\circ} \mathrm{C}, 40 \%\right.$ humidity $)$. To prepare grain for screening, 30 grains from each plot were placed in a $15-\mathrm{ml}$ conical tube and washed with $95 \%$ ethanol for $2 \mathrm{~min}$, followed by $1 \%$ sodium hypochlorite $(\mathrm{NaClO})$ with $0.01 \%$ Tween 20 (Sigma) for $10 \mathrm{~min}$, using continuous gentle rocking, and then rinsed three times in sterile purified water (Labconco, Kansas City, MO). The grain samples were dried in a laminar-flow hood. Grain was aseptically applied to DRBC, DCPA, and PCNB media at five grains per medium. Grains with fungal growth were enumerated for each medium.

Individual fungal colonies growing from each grain onto the medium were transferred to PDA. Colony morphology on PDA, and conidiophore structures, conidial types, and conidial morphologies on appropriate sporulation media were used to identify Fusarium, Alternaria, and Cochliobolus spp. $(6,32,45,66)$. Fungal infection of each grain was enumerated for the following categories: presence of fungal growth, Alternaria spp., Fusarium in the Gibberella fujikuroi species complex (SC), Fusarium spp. not in the G. fujikuroi ("other Fusarium spp.'), and members of the Cochliobolus SC.

Because several Fusarium spp. infect sorghum grain (14,17), many of which are difficult to distinguish due to lack of morphological characteristics and variability in culture (18), molecular identification using sequences from the translation elongation factor gene (TEF) was conducted. A subset of representative isolates from grain of each plot was randomly chosen for molecular identification. Isolates were single-spored and DNA was extracted from ground, lyophilized mycelium (31). The $5^{\prime}$ region of $T E F$ was polymerase chain reaction (PCR)-amplified using primers EF-1 and EF-2 (18). Amplification products were sequenced and sequences were assembled using Sequencher 4.10.1 (Gene Codes Corp., Ann Arbor, MI). Assembled sequences were compared with those in the publically available FUSARIUM-ID database (http://isolate.fusariumdb.org/index.php) (18). Sequences were submitted to GenBank as accession numbers KM462914 through KM463008.

Percentage of grain infected by fungi within a category were analyzed to determine effects of waxy phenotype (wild-type or waxy) and presence or absence of GBSS in waxy grains. Results obtained from each medium were analyzed separately using PROC MIXED of SAS/STAT software (54). Years (2004 and 2005), lines (23 wild-type; 25 waxy, GBSS ${ }^{-}$; and 4 waxy, $\mathrm{GBSS}^{+}$), and replications (four per year) were considered random variables. Grain phenotype was the only fixed variable. In the MODEL statement, the DDFM $=\mathrm{KR}$ option was specified to calculate denominator degrees of freedom using the Kenward-Rogers method (25). Levene's homogeneity of variance tests were conducted for each class variable, which indicated heterogeneity in covariance structure of some class variables. On the basis of these results, the REPEATED/GROUP option of PROC MIXED (54) was used to specify those structures, as appropriate. For each medium, the percent of grain infected in each of the five categories was the dependent variable. In the text and tables, means are expressed as least squares means followed by the standard error. Pearson correlations were generated for the response variables days to anthesis, height at maturity, and percentage of grain with internal fungal infection as determined on DCPA, PCNB, and DRBC using SAS Proc Corr software (45). Correlations were also generated for the same response variables and peak starch gelatinization temperatures (previously reported) for the two replications that this study overlaps with the previous study (50). Wild-type; waxy, GBSS ${ }^{-}$; and waxy, GBSS ${ }^{+}$were conducted separately.

Sorghum has four loci, $D w 1$ through $D w 4$, that control plant height; forage types tend to have recessive alleles at one or two loci while grain types have recessive alleles at three loci (67). Since previous research suggested that plant height was a factor in determining susceptibility to grain mold (67), a preliminary correlation analysis comparing plant height with grain infection levels was conducted. This analysis indicated that plant height could not be discounted as a factor in the results. To determine if the distribution of plant height at maturity for each grain phenotype was a covariate of the mean percentage of grain infected with fungi, partial correlations were made with SAS/STAT software (54) using the MANOVA/PRINTE statement in PROC GLM. Based on these results, percent of grain with internal fungal infection for PI 23231, PI 217897, PI 535783, PI 563015, PI 563402, PI 563670, PI 563671, PI 563672, PI 565116, PI 567939, PI 586448, and PI 667647 were compared with phenotype and height class (Table 1) using PROC MIXED of SAS/STAT software (54) as described above.

Grain inoculations. Grain inoculations were performed on lines described in Tables 1 and 2, using previous protocols with modifications $(4,13)$. Experiment 1 used PIs indicated with asterisks in Table 1, experiment 2 used near-isogenic $w x^{a}$ or $w x^{b}$ lines and their corresponding wild-type lines, listed in Table 2, and experiment 3 used $w x^{a}$ and $w x^{b}$ lines, also listed in Table 2. For each repetition, five sets of 50 seeds were washed as described above, except wash times were extended by 3 and 5 min, respectively. After rinsing in sterile purified water and drying, four sets of 50 seeds from each line were placed into individual polystyrene petri dishes

TABLE 2. Sorghum near-isogenic line pairs, $W x$ and $w x^{a}, W x$ and $w x^{b}$, and $w x^{a}$ and $w x^{b}$, utilized in this study

\begin{tabular}{lclc}
\hline Line $^{\mathrm{v}}$ & Pair $^{\mathrm{w}}$ & Phenotype & Genotype $^{\mathrm{y}}$ \\
\hline$W x$ and $w x^{a}$ or $w x^{b}$ & & & \\
$\mathrm{~N} 619$ & 1 & waxy & $w x^{b}$ \\
$\mathrm{~N} 620$ & 1 & Wild-type & $W x$ \\
$\mathrm{~N} 621$ & 2 & waxy & $w x^{a}$ \\
$\mathrm{~N} 622$ & 2 & Wild-type & $W x$ \\
$\mathrm{~N} 623$ & 3 & waxy & $w x^{a}$ \\
$\mathrm{~N} 624$ & 3 & Wild-type & $W x$ \\
$\mathrm{~N} 625$ & 4 & waxy & $w x^{b}$ \\
$\mathrm{~N} 626$ & 4 & Wild-type & $W x$ \\
$\mathrm{~N} 627$ & 5 & waxy & $w x^{b}$ \\
$\mathrm{~N} 628$ & 5 & Wild-type & $W x$ \\
$\mathrm{~N} 629$ & 6 & waxy & $w x^{a}$ \\
$\mathrm{~N} 630$ & 6 & Wild-type & $W x$ \\
$\mathrm{~N} 631$ & 7 & waxy & $w x^{b}$ \\
$\mathrm{~N} 632$ & 7 & Wild-type & $W x$ \\
$\mathrm{~N} 633$ & 8 & waxy & $w x^{b}$ \\
$\mathrm{~N} 634$ & 8 & Wild-type & $W x$ \\
$\mathrm{~N} 635$ & 9 & waxy & $w x^{b}$ \\
$\mathrm{~N} 636$ & 9 & Wild-type & $W x$ \\
$\mathrm{~N} 637$ & 10 & waxy & $w x^{a}$ \\
$\mathrm{~N} 638$ & 10 & Wild-type & $W x$ \\
$\mathrm{~N} 639$ & 11 & waxy & $w x^{a}$ \\
$\mathrm{~N} 640$ & 11 & Wild-type & $W x$ \\
$\mathrm{U}$ & 12 & waxy & $w x^{a}$ \\
$\mathrm{U}$ & 12 & Wild-type & $W x$ \\
$w x^{a}$ and $w x^{b}$ & & & \\
$\mathrm{U}$ & 1 & waxy & $w x^{a}$ \\
$\mathrm{U}$ & 1 & waxy & $w x^{b}$ \\
$\mathrm{U}$ & 2 & waxy & $w x^{a}$ \\
$\mathrm{U}$ & 3 & waxy & $w x^{b}$ \\
$\mathrm{U}$ & waxy & $w x^{a}$ \\
$\mathrm{U}$ & 2 & waxy & $w x^{b}$ \\
\hline $\mathrm{N} 60$ & & & \\
\hline
\end{tabular}

$\mathrm{N}$ followed by a number refers to Agricultural Research Division, Institute of Agriculture and Natural Resources (75).

${ }^{w}$ Lines with the same pair number are near-isogenic. Refer to Materials and Methods for details.

${ }^{\mathrm{x}}$ Waxy indicates starch with low (0 to $2 \%$ ) amylose while wild-type indicates normal (22 to $24 \%$ ) amylose starch.

y The wild-type Waxy gene ( $W x$ ) encodes for the protein granule bound starch synthase (GBSS), associated with starch granules $\left(\mathrm{GBSS}^{+}\right)$. $w x^{a}$ lines have starch granules lacking GBSS $\left(\mathrm{GBSS}^{-}\right) ; w x^{b}$ lines have a partially active GBSS protein associated with the starch granule $\left(\mathrm{GBSS}^{+}\right)$.

${ }^{\mathrm{z}} \mathrm{U}$ indicates the line is unreleased. See Materials and Methods for genetic background information 
$(60 \times 15 \mathrm{~mm})($ Falcon, BD Labware, Franklin Lakes, NJ). Conidial suspensions were prepared in sterile purified water, quantified using a hemocytometer, and diluted to $1 \times 10^{3}$ conidia $\mathrm{ml}^{-1}$. For each line, $10 \mathrm{ml}$ of each conidial suspension was added to each of three petri dishes and $10 \mathrm{ml}$ of sterile purified water (control) was added to the fourth petri dish. The petri dishes were incubated in the dark at $25^{\circ} \mathrm{C}$ for 2 days and then in the dark at $4^{\circ} \mathrm{C}$ for 2 days. Two days after the start of the experiment, for the fifth set of 50 grains, a standard germination protocol was conducted by placing the grain into a previously prepared, sterilized glass petri dish $(100 \mathrm{~mm})$ containing paper towels saturated with purified water, and then incubating for 2 days at $25^{\circ} \mathrm{C}$ (null treatment) (13). Grain germination for all treatments was scored based on growth of the radicle and shoot past the length of each seed.

For each treatment (three fungal inoculations, water or null), seven germinated seeds were planted, using surface-disinfested forceps, into soil mix (one part sand, one part coarse vermiculite, one part top soil and two parts shredded peat moss) previously moistened with either purified water (PIs, Ellis, and wild-type lines) or sterile purified water (near-isogenic lines, RTx430 and Wheatland), and then covered with vermiculite. A single germinated seed was planted in a Ray Leach "Cone-tainer" (Stuewe \& Sons, Inc., Corvalis, OR), $3.8 \mathrm{~cm}$ diameter at the top by $21 \mathrm{~cm}$ long, which was then placed in a rectangular rack that holds 98 Cone-tainers in a $7 \times$ 14 grid. Reverse osmosis (RO) water was purified using a four filter (one carbon and three deionizing) general chemistry polishing system with a hollow fiber final filter with $0.2 \mu \mathrm{m}$ pore size to remove bacteria (Labconco). Water was dispensed to Cone-tainers

TABLE 3. Percentage of field-grown wild-type or waxy grain, with the presence $(+)$ or absence $(-)$ of granule bound starch synthase (GBSS) in starch granules, infected by total fungi, Alternaria spp., members of the Cochliobolus species complex (SC), members of the Gibberella fujikuroi SC, and other Fusarium spp., in plant introductions (PI) and other lines, as determined on three semiselective mediav

\begin{tabular}{lccc}
\hline & \multicolumn{2}{c}{ Phenotype, GBSS ${ }^{+-}$(percent) } \\
\cline { 2 - 4 } Medium & $\begin{array}{c}\text { Wild-type, } \\
\text { GBSS }\end{array}$ & $\begin{array}{c}\text { waxy, } \\
\text { GBSS }\end{array}$ & $\begin{array}{c}\text { waxy } \\
\text { GBSS }^{+}\end{array}$ \\
\hline DCPA $^{w}$ & & & \\
Total fungi & $10.0 \mathrm{~b}^{\mathrm{x}} \pm 5.8$ & $11.3 \mathrm{~b} \pm 5.7$ & $26.9 \mathrm{a} \pm 7.9$ \\
Alternaria spp. & $3.3 \mathrm{~b} \pm 1.9$ & $7.0 \mathrm{ab} \pm 1.9$ & $16.3 \mathrm{a} \pm 5.1$ \\
Cochliobolus SC & $0.0 \mathrm{~b} \pm 0.1$ & $0.1 \mathrm{~b} \pm 0.1$ & $0.6 \mathrm{a} \pm 0.3$ \\
Gibberella fujikuroi SC & $4.4 \mathrm{~b} \pm 4.4$ & $4.5 \mathrm{~b} \pm 4.4$ & $5.7 \mathrm{a} \pm 4.5$ \\
Other Fusarium spp. & $0.8 \mathrm{a} \pm 0.3$ & $0.6 \mathrm{a} \pm 0.4$ & $0.6 \mathrm{a} \pm 0.7$ \\
PCNB & & & \\
Total fungi & $4.5 \mathrm{~b} \pm 4.1$ & $4.4 \mathrm{~b} \pm 4.1$ & $6.9 \mathrm{a} \pm 4.1$ \\
Gibberella fujikuroi SC & $4.0 \mathrm{a} \pm 2.7$ & $1.5 \mathrm{a} \pm 2.7$ & $8.1 \mathrm{a} \pm 4.3$ \\
Other Fusarium spp. & $0.4 \mathrm{a} \pm 0.4$ & $0.3 \mathrm{a} \pm 0.4$ & $0.6 \mathrm{a} \pm 0.8$ \\
DRBCz & & & \\
Total fungi & $10.1 \mathrm{~b} \pm 5.9$ & $10.7 \mathrm{~b} \pm 5.9$ & $16.9 \mathrm{a} \pm 6.4$ \\
Alternaria spp. & $4.4 \mathrm{a} \pm 1.9$ & $6.1 \mathrm{a} \pm 1.9$ & $10.6 \mathrm{a} \pm 4.0$ \\
Cochliobolus SC & $0.0 \mathrm{a} \pm 0.1$ & $0.1 \mathrm{a} \pm 0.1$ & $0.0 \mathrm{a} \pm 0.2$ \\
Gibberella fujikuroi SC & $4.5 \mathrm{a} \pm 4.3$ & $4.2 \mathrm{a} \pm 4.3$ & $4.3 \mathrm{a} \pm 4.4$ \\
Other Fusarium spp. & $0.4 \mathrm{a} \pm 0.2$ & $0.2 \mathrm{a} \pm 0.2$ & $0.6 \mathrm{a} \pm 0.5$ \\
\hline
\end{tabular}

${ }^{v}$ Grain was surface-disinfested, dried, and plated onto three semiselective media. Each grain with fungal growth was counted to determine percent infected by total fungi. Fungal colonies growing onto the medium were transferred and identified using morphological characteristics to determine percentage of grain infected by those in each of the fungal groups.

w Dicholoran chloramphenicol peptone agar (DCPA) is semiselective for Fusarium spp., and Alternaria spp. and other dark-spored ascomycetes.

$x$ Data were analyzed using PROC MIXED procedure of SAS/STAT software (54) by comparing percentage of grain with colonies within a fungal group for a plant phenotype, as detected on a given medium. Least squares means and standard errors are shown. Different letters (across rows, comparing plant phenotypes) indicate that comparisons are significant at $P \leq 0.05$.

y Pentachloronitrobenzene (PCNB) agar is semiselective for Fusarium spp.; thus, only percent infection by $G$. fujuikuroi SC members and other Fusarium spp. are shown.

${ }^{\mathrm{z}}$ Dichloran rose bengal chloramphenicol (DRBC) agar is a general purpose fungal medium. with sterilized apparatuses constructed from 50-ml conical tubes. Immediately after planting, germinated seeds were fertilized with $10 \mathrm{ml}$ of sterilized one-third strength Hoagland's solution lacking micronutrients prepared with purified water. Cone-tainers were watered with $10 \mathrm{ml}$ of water, three times per week.

Three weeks after planting, seedling emergence and survival were recoded. Aboveground fresh weight of emerged plants was determined; if weight was indicated as 0.00 on the balance, " $0.004 \mathrm{~g}$ " was recorded (just below the level of detection).

The experimental design for PIs (experiment 1) was a randomized incomplete block (RIB) with three replications ( 10 entries in blocks 1 and 2 and 11 in block 3), planted every two weeks, for each of 31 lines and five treatments (Alternaria sp., C. sorghina, or $F$. thapsinum conidia, or water or null controls) per line. The experimental design for the near-isogenic $w x^{a}$ and $w x^{b}$ lines, and their wild-type counterparts (experiment 2), was also a RIB (blocks 1 and 2 each had six entries and blocks 3 and 4 each had seven) with three replications per line with 22 lines and five treatments per line. For experiments 1 and 2, lines were randomly assigned to a block within each replication. The experimental design for $w x^{a}$ and $w x^{b}$ near-isogenic lines (experiment 3) was a RCB with three replications with 10 lines and five treatments per line. For all three experiments, each line was planted in five adjacent rows of Conetainers (whole plot) and treatments were randomly assigned to a row of seven Cone-tainers (split plot). Percent germination, and percent emergence and survival following planting, and fresh weights of emergent plants were analyzed separately using PROC MIXED of SAS/STAT software (54). Replication was considered a random effect. For PIs, grain type (wild-type and waxy), phenotype (GBSS ${ }^{+-}$), and treatment (Alternaria sp., $F$. thapsinum, C. sorghina) were considered fixed effects. For near-isogenic lines, genotype and pair (Table 2), as well as treatment, were considered fixed effects. The KENWARD-ROGER option was specified for estimating degrees of freedom. Least squares means, and differences among least squares means were compared using the DIFF option. Data from PI inoculations were analyzed by comparing grain type (waxy versus wild-type) and by comparing the three phenotypes (wild-type; waxy, GBSS + ; and waxy, $\mathrm{GBSS}^{-}$). The measurements percent germination, emergence or survival, were analyzed separately. Analysis of aboveground weights of individual plants was confounded because certain treatments had high numbers of Cone-tainers with no emergent plants, resulting in missing data (e.g., amount of missing data were treatment-dependent). Therefore, mean weight of emergent plants per row was estimated and these values $(n=3)$ were used in analyses.

\section{RESULTS}

Marker and iodine analyses of GBSS- and GBSS ${ }^{+}$waxy PIs. To determine whether the GBSS- lines contained the $w x^{a}$ allele and the GBSS ${ }^{+}$lines contained $w x^{b}$, marker analyses were performed. Multiplex PCR of DNA from GBSS- waxy PIs revealed that all but one PI had the PCR product size indicative of the $w x^{a}$ allele; PI 562758 produced a product size similar to that of wild-type lines, even though it possesses waxy starch (Table 1). CAPS marker analysis of DNA from $\mathrm{GBSS}^{+}$waxy PIs revealed that two (PI 563670 and PI563671) had the restriction pattern similar to known $w x^{b}$ cultivars and two (PI 23231 and PI 217897) were not digested by NcoI and had the wild-type sized band. Iodine staining was repeated (from a previous study) on grain from PI 23231, PI 217897 and PI 548008, along with controls BWheatland (wild-type) and 94C289 (waxy). The three PIs all resulted in a purple iodine response, while BWheatland scored royal blue and 94C289 also scored purple; these results are similar to what was previously observed (50).

Field study. When grain were screened and fungi selected on DCPA media, GBSS ${ }^{+}$waxy grain had significantly more infection by Alternaria spp., and members of the Cochliobolus and 
G. fujikuroi SC than wild-type grain $(P=0.02$; Table 3$)$. GBSS $^{-}$ waxy grain had similar levels of infection to wild-type grain in these three fungal groups $(P \geq 0.09)$. For other Fusarium spp. detected on DCPA, for G. fujikuroi SC isolates and other Fusarium spp. isolates detected on PCNB, and for all four fungal groups detected on DRBC, there were no significant differences between the three grain phenotypes for percentage of fungal infection (Table 3).

Alternaria spp. were identified to species using morphological techniques and Fusarium spp. were also identified using morphological techniques, which were confirmed using molecular identification. The most commonly isolated Alternaria spp. was by far A. alternata (Fr.) Keissl. 1912, but also detected were A. arborescens E.G. Simmons 1999, A. dumosa E.G. Simmons 1999, A. gaisen Nagano 1920, and A. longipes (Ellis \& Everh.) E.W. Mason 1928. The G. fujikuroi SC species found in grain were F. thapsinum, which was most prevalent. F. proliferatum (Matsush.) Nirenberg, F. andiyazi Marasas, Rheeder, Lampr., K.A. Zeller \& J.F. Leslie 2001, and F. subglutinans (Wollenw. \& Reinking) P.E. Nelson, Toussoun \& Marasas 1983 (Supplementary Table 1), The only other Fusarium spp. detected was $F$. incarnatum-F. equiseti species complex (FIESC) genotype 25-a, b, c.

Because of the variety of sorghum lines utilized in this study, correlation analyses were used to compare the physical parameters, plant height at maturity, and days to anthesis, when examining

TABLE 4. Pearson correlation coefficient $(r)$ and probability $(P)$ for the variables days to anthesis, height, and percent of grain with internal fungal infection, as determined on three media, for wild-type; waxy, granule bound starch synthase $(\mathrm{GBSS})^{-}$; and waxy, $\mathrm{GBSS}^{+}$plant introductions and other lines ${ }^{\mathrm{x}}$

\begin{tabular}{|c|c|c|c|c|}
\hline \multirow[b]{2}{*}{ Variables } & \multirow{2}{*}{$\begin{array}{l}\text { Height at } \\
\text { anthesis }\end{array}$} & \multicolumn{3}{|c|}{ Percent grain with fungi selected on } \\
\hline & & $\mathrm{DCPA}^{\mathrm{z}}$ & $\mathrm{PCNB}^{\mathrm{z}}$ & $\mathrm{DRBC}^{\mathrm{z}}$ \\
\hline \multicolumn{5}{|l|}{ Wild-type $(n=192)$} \\
\hline Days to anthesis & $\begin{array}{l}r=0.17 \\
P=0.02\end{array}$ & $\begin{array}{l}r=-0.16 \\
P=0.02\end{array}$ & $\begin{array}{l}r=0.17 \\
P=0.02\end{array}$ & $\begin{array}{l}r=-0.25 \\
P<0.01\end{array}$ \\
\hline Height & & $\begin{array}{l}r=-0.39 \\
P<0.01\end{array}$ & $\begin{array}{l}r=-0.41 \\
P<0.01\end{array}$ & $\begin{array}{l}r=-0.41 \\
P<0.01\end{array}$ \\
\hline DCPA & & & $\begin{array}{l}r=0.75 \\
P<0.01\end{array}$ & $\begin{array}{l}r=0.77 \\
P<0.01\end{array}$ \\
\hline $\mathrm{PCNB}$ & & & & $\begin{array}{l}r=0.58 \\
P<0.01\end{array}$ \\
\hline \multicolumn{5}{|c|}{ waxy, $\mathrm{GBSS}^{-}(n=200)$} \\
\hline Days to anthesis & $\begin{array}{l}r=0.15 \\
P=0.04\end{array}$ & $\begin{array}{l}r=-0.09 \\
P=0.19\end{array}$ & $\begin{array}{l}r=-0.06 \\
P=0.36\end{array}$ & $\begin{array}{l}r=-0.09 \\
P=0.18\end{array}$ \\
\hline Height & & $\begin{array}{l}r=-0.36 \\
P<0.01\end{array}$ & $\begin{array}{l}r=-0.25 \\
P<0.01\end{array}$ & $\begin{array}{l}r=-0.21 \\
P<0 / 01\end{array}$ \\
\hline DCPA & & & $\begin{array}{l}r=0.58 \\
P<0.01\end{array}$ & $\begin{array}{l}r=0.71 \\
P<0.01\end{array}$ \\
\hline PCNB & & & & $\begin{array}{l}r=0.50 \\
P<0.01\end{array}$ \\
\hline \multicolumn{5}{|c|}{ waxy, $\mathrm{GBSS}^{+}(n=32)$} \\
\hline Days to anthesis & $\begin{array}{l}r=-0.16 \\
P=0.37\end{array}$ & $\begin{array}{l}r=-0.18 \\
P=0.31\end{array}$ & $\begin{array}{l}r=-0.42 \\
P=0.02\end{array}$ & $\begin{array}{l}r=-0.22 \\
P=0.23\end{array}$ \\
\hline Height & & $\begin{array}{l}r=-0.59 \\
P<0.01\end{array}$ & $\begin{array}{l}r=-0.22 \\
P=0.23\end{array}$ & $\begin{array}{l}r=-0.57 \\
P<0.01\end{array}$ \\
\hline DCPA & & & $\begin{array}{l}r=0.63 \\
P<0.01\end{array}$ & $\begin{array}{l}r=0.66 \\
P<0.01\end{array}$ \\
\hline PCNB & & & & $\begin{array}{l}r=0.47 \\
P=0.01\end{array}$ \\
\hline
\end{tabular}

x Pearson correlations were generated for the response variables days to anthesis, height at maturity, percentage of grain with internal fungal infection as determined on dicholoran chloramphenicol peptone agar (DCPA), pentachloronitrobenzene (PCNB) agar, and dichloran rose bengal chloramphenicol (DRBC) agar using SAS Proc Corr software (54).

y Average plant height in each plot was estimated when the plants in a plot reached anthesis (defined as half the plants having anthers exerted).

$\mathrm{z}$ To determine internal fungal infection, grain was surface-disinfested, dried, and plated onto DCPA, PCNB, and DRBC. DCPA is semiselective for Fusarium spp. and Alternaria spp. and other dark-spored ascomycetes. PCNB is semiselective for Fusarium spp. DRBC is a general purpose fungal medium. Each grain with fungal colonies growing onto the medium was counted. percent of grain with fungal infection (Table 4). Internal fungal infection was significantly negatively correlated with plant height for each of three phenotypic classes (wild-type; waxy, GBSS ${ }^{-}$; and waxy, GBSS $\left.{ }^{+}\right)$when fungi were selected on DCPA $(r \leq-0.36 ; P<$ $0.01)$ and DRBC $(r \leq-0.21 ; P<0.01)$ media; additionally, for wildtype and GBSS $^{-}$waxy grain, height was significantly negatively correlated with plant height when fungi were selected on PCNB $(r \leq$ $-0.25 ; P<0.01)$ but not for $\mathrm{GBSS}^{+}$waxy grain $(r=-0.22 ; P=0.23)$ (Table 4). Analyses of percentage of grain across all plant phenotypes with members of individual fungal genera or of the G. fujikuroi SC revealed significant negative correlation between height at anthesis and percentage of grain with Alternaria spp. (on DCPA, $r=-0.39, P<0.01$; on DRBC, $r=-0.34, P<0.01)$, G. fujikuroi SC (on DCPA, $r=-0.25, P<0.01$; on DRBC, $r=-0.19$, $P<0.01$; on PCNB, $r=-0.19, P=0.05)$, and other Fusarium spp. (on DCPA, $r=-0.11, P=0.02$; on PCNB, $r=-0.22, P<0.01$; on DRBC, $r$ not significant at $P=0.08$ ). To examine the role of plant height in grain mold further, a subset of 12 lines, representing two significantly different height classes $(P<0.01$; Table 1$)$ were compared for fungal infection of grain on DCPA, PCNB, and DRBC (Table 5). For all three tall plant phenotypes, there were no significant differences for fungi infecting grain selected on all three media $(P \geq 0.20)$. However, waxy $\mathrm{GBSS}^{+}$short plants had significantly greater percentages of grain with internal fungal growth than grain from short waxy GBSS $^{-}$plants, when selected on DCPA or DRBC media $(P \leq 0.05)$ (Table 5). On these two media, there were also significantly greater percentages of infected grain from short wild-type and waxy $\mathrm{GBSS}^{+}$plants than tall ones within the same waxy phenotype $(P \leq 0.02)$.

Correlation analyses were also conducted utilizing two repetitions from 2004 that were previously analyzed for gelatinization temperatures (50). When peak gelatinization temperatures were compared with percent fungal infection found in grain of the three phenotypes (wild-type, waxy $\mathrm{GBSS}^{-}$, and waxy $\mathrm{GBSS}^{+}$) correlations were not significant $(r \leq 0.68 ; P \geq 0.06)$.

TABLE 5. Mean percent grain with internal fungal infection of short or tall, wild-type with granule bound starch synthase present in grain $\left(\mathrm{GBSS}^{+}\right)$, waxy $\mathrm{GBSS}^{-}$, or waxy $\mathrm{GBSS}^{+}$sorghum plants, as determined on three semiselective media $^{\text {w }}$

\begin{tabular}{lccrc}
\hline & & \multicolumn{3}{c}{ Percent infected grain } \\
\cline { 3 - 5 } Medium $^{\mathrm{x}}$ & Height $^{\mathrm{y}}$ & Wild-type, GBSS $^{+}$ & waxy, GBSS & waxy, GBSS \\
\hline DCPA & Short & $25.0 \mathrm{~b}^{* \mathrm{z}} \pm 7.9$ & $18.8 \mathrm{~b} \pm 7.9$ & $48.8 \mathrm{a}^{*} \pm 7.9$ \\
DCPA & Tall & $7.5 \mathrm{a} \pm 6.1$ & $8.8 \mathrm{a} \pm 6.1$ & $5.0 \mathrm{a} \pm 6.1$ \\
PCNB & Short & $7.9 \mathrm{a} \pm 5.3$ & $6.8 \mathrm{a} \pm 5.1$ & $11.0 \mathrm{a} \pm 5.4$ \\
PCNB & Tall & $4.4 \mathrm{a} \pm 5.3$ & $3.6 \mathrm{a} \pm 5.1$ & $4.6 \mathrm{a} \pm 5.4$ \\
DRBC & Short & $30.0 \mathrm{a} \mathrm{b}^{*} \pm 7.4$ & $15.0 \mathrm{~b} \pm 7.4$ & $31.3 \mathrm{a}^{*} \pm 7.4$ \\
DRBC & Tall & $8.8 \mathrm{a} \pm 5.7$ & $6.3 \mathrm{a} \pm 5.7$ & $2.5 \mathrm{a} \pm 5.7$
\end{tabular}

${ }^{w}$ Grain was surface-disinfested, dried and plated onto three semiselective media. Grains with fungal growth were counted. GBSS is the enzyme responsible for amylose production in wild-type plants. It is absent in starch granules of many waxy (no amylose) plants $\left(\mathrm{GBSS}^{-}\right)$, but is present (partially active) in starch granules of a few waxy lines $\left(\mathrm{GBSS}^{+}\right)$.

${ }^{x}$ Dichloran chloramphenicol peptone agar (DCPA) is semiselective for Fusarium spp. and Alternaria spp. and other dark-spored ascomycetes. Pentachloronitrobenzene (PCNB) agar is semiselective for Fusarium spp. Dichloran rose bengal chloramphenicol (DRBC) agar is a general purpose fungal medium.

y Two lines of each waxy $\left(\mathrm{GBSS}^{+/-}\right)$phenotype and height class were chosen for analysis (Table 1). The lines were PI 23231, PI, 217897, PI 535783, PI 563015, PI 563402, PI 563670, PI 563671, PI 563672, PI 565116, PI 567939, PI 586448, and PI 667647. Difference in heights between short and tall plants was significant $(P<0.01)$.

z Data were analyzed using PROC MIXED procedure of SAS/STAT software (54). Comparisons were made of percent of grain with colonies for a height class, as detected on a given medium. Differing letters indicate that comparisons are significant at $P \leq 0.05$. Comparisons also were made between percent of grain with colonies from short and tall plants within a plant phenotype as detected on a given medium. An asterisk indicates the value is significantly greater than the comparable value at $P \leq 0.05$. 
Grain inoculations. In experiment 1, fungal conidia inoculations or water treatments did not affect germination of grain from wild-type PIs $(P \geq 0.12)$ (Table 6). Similar to wild-type, waxy GBSS $^{-}$PIs mean percent germination was not significantly different than the water control $(P \geq 0.07)$. Mean percent germination was reduced for grain of $\mathrm{GBSS}^{+}$waxy PIs by inoculation with Alternaria sp. and $C$. sorghina when compared with water controls $(P \leq 0.04)$; subsequent measurements using the same inoculated seed were not significantly reduced $(P \geq 0.06)$. However, emergence, survival, and mean plant weight of wild-type or $\mathrm{GBSS}^{-}$waxy grain inoculated with $C$. sorghina or $F$. thapsinum could be reduced compared with water controls (Table 6).

When response of waxy PIs was compared with that of wild-type PIs, inoculations of $\mathrm{GBSS}^{-}$grain did not have reduced germination $(P \geq 0.08)$, but had significantly reduced mean percent emergence (C. sorghina) and survival (Alternaria $\mathrm{sp}$. and $C$. sorghina $)(P=$ 0.04 ) (Table 6). Inoculation of waxy $\mathrm{GBSS}^{+}$grain by Alternaria sp. and $C$. sorghina reduced germination compared with wild-type grain $(P \leq 0.05)$, but mean percent emergence and survival, and mean fresh weight, were similar to wild-type $(P \geq 0.37)$. Treatment of waxy $\mathrm{GBSS}^{+}$grain with $F$. thapsinum conidia did not significantly affect responses compared with wild-type $(P \geq 0.11)$.

In experiment 2, 12 near-isogenic pairs, in different genetic backgrounds, were used to directly compare effects of either $w x^{a}$ or $w x^{b}$ to wild-type (75) (this work). There was no consistent effect indicating that waxy increased susceptibility to any of the three fungi relative to wild-type; e.g., seedling weights were not significantly affected (Table 7). $w x^{a}$ grain was not significantly affected by inoculation when comparing wild-type grain with the same treatment, for any of the four measurements $(P \geq 0.52)$. However, following inoculations with $C$. sorghina or $F$. thapsinum, mean percent emergence of $w x^{b}$ grain was significantly less than wild-type grain (Table 7). Interestingly, mean seedling weights were significantly greater for Alternaria-treated $w x^{b}$ grain, as well as for untreated grain compared with wild-type grain. Comparisons of individual waxy isogenic line and comparable wild-type line within individual pairs revealed that germination was significantly reduced in inoculated waxy grain from line pair 5 (Alternaria $\mathrm{sp}$. and F. thapsinum), 6 (C. sorghina and F. thapsinum), 7 (C. sorghina), 9 (C. sorghina and F. thapsinum), and 12 (Alternaria sp.) $(P \leq 0.04)$ (Table 2; Supplementary Table 2). Seedling emergence and survival were significantly reduced in the waxy line of pair 4 after inoculation with $F$. thapsinum $(P=0.05)$, and in the waxy line of pair 8 inoculated with $C$. sorghina $(P \leq 0.02)$, compared with respective wild-type lines. The waxy lines from pairs 1 and 4 had significantly greater percent germination $(P=0.01)$ and mean plant weight $(P=0.02)$, following Alternaria sp. inoculation, and the waxy line from pair 9 had significantly greater mean seedling plant weight following inoculation with $F$. thapsinum, than their nearisogenic wild-type counterparts.

To directly compare the $w x^{a}\left(\mathrm{GBSS}^{-}\right)$and $w x^{b}\left(\mathrm{GBSS}^{+}\right)$alleles, near-isogenic pairs were developed (Table 2) (M. K. Yerka, J. J. Toy, D. L. Funnell-Harris, S. E. Sattler, and J. F. Pedersen, unpublished data). In experiment 3 , grain from these three isogenic line pairs also were inoculated with Alternaria sp., F. thapsinum, and $C$. sorghina conidia. There were no significant differences between $w x^{a}$ and $w x^{b}$ for any of the treatments and the untreated control $(P \geq$ 0.11) (Table 8). C. sorghina treatment significantly reduced emergence, survival, and plant weight for both $w x$ genotypes compared with water controls, and likewise, $F$. thapsinum significantly reduced seedling survival and plant weight $(P \leq 0.01)$ for both $w x$ genotypes. Again, there was no case where a significant difference was observed between $w x^{a}$ and $w x^{b}$ alleles near-isogenic pairs following fungal conidia treatment $(P \geq 0.13)$ (Table 2; Supplementary Table 3).

\section{DISCUSSION}

The results presented herein indicated that the use of the waxy trait to increase usability of sorghum grain for food products, feed, and grain-based bioenergy $(34,53,73,74)$ will not result in increased susceptibility to grain mold pathogens. These results were obtained

TABLE 6. Grain from sorghum plant introductions that are wild-type, or waxy that either lack granule bound starch synthase (GBSS-) or have the GBSS protein $\left(\mathrm{GBSS}^{+}\right)$in starch granules were treated with Alternaria sp., Curvularia sorghina or Fusarium thapsinum conidia, or water or were untreated ${ }^{\mathrm{x}}$

\begin{tabular}{|c|c|c|c|c|c|}
\hline \multirow[b]{2}{*}{ Assessment } & \multicolumn{3}{|c|}{ Conidial treatments } & \multicolumn{2}{|c|}{ Controls } \\
\hline & Alternaria sp. & C. sorghina & F. thapsinum & Water & Untreated \\
\hline \multicolumn{6}{|l|}{ Wild-type grain } \\
\hline Germination & $71.8 \mathrm{a}^{\mathrm{y}} \pm 4.4$ & $73.7 \mathrm{a} \pm 4.4$ & $74.8 \mathrm{a} \pm 4.4$ & $72.8 \mathrm{a} \pm 4.4$ & $75.0 \mathrm{a} \pm 4.4$ \\
\hline Survival & $58.5 b c \pm 13.7$ & $54.0 \mathrm{c} \pm 13.7$ & $50.8 \mathrm{c} \pm 13.7$ & $66.7 \mathrm{ab} \pm 13.7$ & $72.1 \mathrm{a} \pm 13.7$ \\
\hline Weight (g) & $0.37 b \pm 0.11$ & $0.28 \mathrm{c} \pm 0.11$ & $0.28 c \pm 0.11$ & $0.40 \mathrm{ab} \pm 0.11$ & $0.45 \mathrm{a} \pm 0.11$ \\
\hline \multicolumn{6}{|l|}{ waxy grain } \\
\hline \multirow{2}{*}{\multicolumn{6}{|c|}{ waxy, GBSS $^{-}$grain }} \\
\hline & & & & & \\
\hline Germination & $74.9 b \pm 4.7$ & $77.8 \mathrm{ab} \pm 4.7$ & $77.2 \mathrm{ab} \pm 4.7$ & $78.9 \mathrm{ab} \pm 4.7$ & $80.9 \mathrm{a} \pm 4.7$ \\
\hline Emergence & $62.6 b c \pm 12.1$ & $55.4 \mathrm{c} * \pm 12.1$ & $59.0 \mathrm{c} \pm 11.8$ & $66.9 b \pm 11.8$ & $76.8 \mathrm{a} \pm 12.0$ \\
\hline Survival & $47.3 b^{*} \pm 13.8$ & $42.9 b^{*} \pm 13.8$ & $44.9 b \pm 13.8$ & $60.4 \mathrm{a} \pm 13.8$ & $67.9 \mathrm{a} \pm 13.8$ \\
\hline Weight (g) & \multicolumn{4}{|c|}{ waxy, $\mathrm{GBSS}^{+}$grain } & $0.44 a \pm 0.11$ \\
\hline
\end{tabular}

${ }^{\mathrm{x}}$ Mean percent germination, emergence and survival, and mean fresh weight $(\mathrm{g})$ were determined. Grain from waxy and wild-type sorghum plant introductions, a known waxy line, and known wild-type lines were incubated in suspensions of conidia or sterile water or germinated without treatment. Percentage of germinated seeds was determined. A subset of germinated seeds was grown for 3 weeks in soil at which time numbers of emerged plants and surviving plants were determined. Fresh weight of above-ground plant parts was determined and analyzed by total weights for a row and then divided by number of surviving plants to determine mean weight per plant.

y Least squares means and standard errors are shown. Within plant genotype and a given assessment, means with different letters are significantly different at $P \leq$ 0.05 .

${ }^{\mathrm{z}}$ Within a treatment and a given assessment, asterisk indicates that the mean of the waxy lines is significantly less than that of the wild-type phenotype at $P \leq 0.05$. 
from screening a diverse collection (PIs) of field-grown grain and in vitro inoculation of grain from PIs with grain mold fungi, and in vitro inoculations of near-isogenic waxy lines with grain mold fungi.

Field-grown grain of the PI collection were assessed for internal fungal infection by Alternaria spp., Fusarium spp., and Cochliobolus SC. Across all genotypes, the most commonly detected species, $A$. alternata, $F$. thapsinum, and $F$. proliferatum, are those known to infect sorghum grain $(14,17,69)$. Greater colonization of members from Alternaria spp., Cochliobolus SC, and G. fujikuroi $\mathrm{SC}$ on waxy $\mathrm{GBSS}^{+}$indicated that these lines are more susceptible to infection (Table 3). Correlation analyses indicated that height was a factor in grain infection for all three phenotypes (wild-type, waxy GBSS $^{-}$, and waxy GBSS $^{+}$) (Table 4). Therefore, a subset of lines was compared within height classes (Table 5), which indicated that short lines tended to have more fungal infection of grain than tall lines, but short waxy $\mathrm{GBSS}^{+}$plants had a higher fungal infection percentage than short lines of the other two phenotypes. The four $\mathrm{GBSS}^{+}$waxy lines are all the known such lines from the extensive U.S. photoperiod insensitive collection (http://www.ars-grin.gov/ npgs/); nonetheless, caution must be observed when making broad conclusions. What is known is that the two short waxy $\mathrm{GBSS}^{+}$plants are $w x^{b}$ and likely related (Table 1), while the two tall cultivars have similar infection levels as the tall wild-type lines (Table 5). Although the two tall waxy lines were $\mathrm{GBSS}^{+}$, they did not carry the $w x^{b}$ allele, as indicated by previously developed markers (56). These new $w x$ alleles, as represented by the tall GBSS+ waxy lines, may provide valuable materials for breeding for new waxy grain production lines.

Plant height was a significant factor affecting fungal infection in this study (Tables 4 and 5). Nearly all the lines were tall and

TABLE 7. Comparison of wild-type (Wx) and waxy $\left(w x^{a}\right.$ or $\left.w x^{b}\right)$ grain in near-isogenic sorghum lines following seed inoculations with Alternaria sp., Curvularia sorghina or Fusarium thapsinum conidia, or water and untreated controls as determined by mean percent germination, emergence and survival, and mean fresh weight $(\mathrm{g})^{\mathrm{v}}$

\begin{tabular}{|c|c|c|c|c|c|c|}
\hline \multirow[b]{2}{*}{ Assessment } & \multirow[b]{2}{*}{ Genotype } & \multicolumn{3}{|c|}{ Conidial treatments } & \multicolumn{2}{|c|}{ Controls } \\
\hline & & Alternaria sp. & C. sorghina & F. thapsinum & Water & Untreated \\
\hline \multicolumn{7}{|c|}{ Combined lines with $w x^{a}$ backgrounds ${ }^{\mathrm{w}}$} \\
\hline Germination & $W x$ & $79.9 \mathrm{a}^{\mathrm{x}} \pm 5.2$ & $77.0 \mathrm{a} \pm 5.2$ & $79.5 \mathrm{a} \pm 5.1$ & $81.7 \mathrm{a} \pm 5.2$ & $72.3 \mathrm{a} \pm 7.2$ \\
\hline Emergence & $W x$ & $81.6 \mathrm{ab} \pm 7.2$ & $65.0 \mathrm{c} \pm 7.3$ & $68.9 b c \pm 8.8$ & $79.2 b \pm 7.1$ & $91.9 \mathrm{a} \pm 6.5$ \\
\hline Survival & $W x$ & $72.5 b \pm 8.0$ & $51.0 \mathrm{c} \pm 8.4$ & $47.9 c \pm 9.6$ & $70.9 b \pm 7.5$ & $89.1 \mathrm{a} \pm 5.5$ \\
\hline Weight (g) & $W x$ & $0.22 b c \pm 0.06$ & $0.15 \mathrm{~cd} \pm 0.05$ & $0.13 \mathrm{~d} \pm 0.05$ & $0.24 b \pm 0.05$ & $0.36 \mathrm{a} \pm 0.05$ \\
\hline Germination & $w x^{a}$ & $75.2 b \pm 5.3$ & $70.9 b \pm 5.2$ & $74.0 \mathrm{~b} \pm 5.1$ & $81.1 \mathrm{a} \pm 5.2$ & $68.1 b \pm 7.2$ \\
\hline Emergence & $w x^{a}$ & $69.2 b \pm 7.2$ & $54.1 \mathrm{c} \pm 7.4$ & $53.3 \mathrm{bc} \pm 8.8$ & $69.2 b \pm 7.2$ & $84.3 \mathrm{a} \pm 6.5$ \\
\hline Survival & $w x^{a}$ & $68.1 b \pm 7.0$ & $50.7 \mathrm{~cd} \pm 8.0$ & $36.4 \mathrm{~d} \pm 8.6$ & $63.4 \mathrm{bc} \pm 8.7$ & $84.8 \mathrm{a} \pm 6.8$ \\
\hline Weight (g) & $w x^{a}$ & $0.26 \mathrm{ab} \pm 0.06$ & $0.13 c \pm 0.05$ & $0.11 \mathrm{c} \pm 0.05$ & $0.24 \mathrm{~b} \pm 0.05$ & $0.31 \mathrm{a} \pm 0.05$ \\
\hline \multicolumn{7}{|c|}{ Combined lines with $w x^{b}$ backgrounds ${ }^{\mathrm{y}}$} \\
\hline Germination & $W x$ & $81.4 b \pm 4.4$ & $82.8 \mathrm{ab} \pm 4.7$ & $83.0 \mathrm{~b} \pm 4.1$ & $87.2 \mathrm{a} \pm 4.4$ & $80.0 \mathrm{ab} \pm 5.9$ \\
\hline Emergence & $W x$ & $71.2 \mathrm{abc} \pm 7.2$ & $59.3 c \pm 7.7$ & $68.8 b c \pm 6.9$ & $76.0 \mathrm{ab} \pm 6.7$ & $83.0 \mathrm{a} \pm 5.8$ \\
\hline Survival & $W x$ & $64.4 \mathrm{a} \pm 9.2$ & $45.3 b \pm 9.2$ & $44.5 b \pm 9.2$ & $65.2 \mathrm{a} \pm 9.2$ & $77.7 \mathrm{a} \pm 9.2$ \\
\hline Weight (g) & $W x$ & $0.15 b c \pm 0.05$ & $0.10 \mathrm{c} \pm 0.05$ & $0.11 \mathrm{c} \pm 0.05$ & $0.18 b \pm 0.05$ & $0.25 \mathrm{a} \pm 0.05$ \\
\hline Germination & $w x^{b}$ & $80.8 \mathrm{a} \pm 4.5$ & $78.4 \mathrm{a} \pm 4.4$ & $79.3 a \pm 4.8$ & $81.4 \mathrm{a} \pm 4.4$ & $77.2 \mathrm{a} \pm 4.5$ \\
\hline Emergence & $w x^{b}$ & $67.6 b \pm 7.4$ & $39.0 \mathrm{c} * \mathrm{z} \pm 7.9$ & $50.9 \mathrm{c} * \pm 7.1$ & $69.2 b \pm 6.9$ & $83.5 a \pm 6.0$ \\
\hline Survival & $w x^{b}$ & $63.1 b \pm 9.4$ & $33.8 \mathrm{c} \pm 9.4$ & $26.6 c \pm 9.4$ & $60.0 b \pm 9.4$ & $79.0 \mathrm{a} \pm 9.4$ \\
\hline Weight (g) & $w x^{b}$ & $0.20 b^{*} \pm 0.05$ & $0.09 \mathrm{c} \pm 0.05$ & $0.11 \mathrm{c} \pm 0.06$ & $0.25 b \pm 0.05$ & $0.37 \mathrm{a}^{*} \pm 0.06$ \\
\hline
\end{tabular}

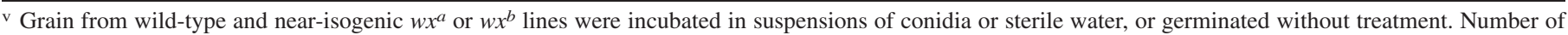
germinated seeds was determined. A subset of germinated seeds was grown for 3 weeks in soil at which time numbers of emerged plants and surviving plants were determined. Fresh weights were determined and analyzed by total weights for a row and then divided by number of emergent plants to determine mean weight per plant.

${ }^{w}$ Data are from grain of six near-isogenic line pairs in backgrounds with two different sources of $w x^{a}$ gene (75) (present work).

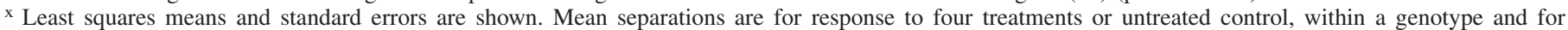
a particular assessment. Means with different letters are significantly different at $P \leq 0.05$.

y Data are from grain of six near-isogenic line pairs in backgrounds with two different sources of $w x^{b}$ gene (75).

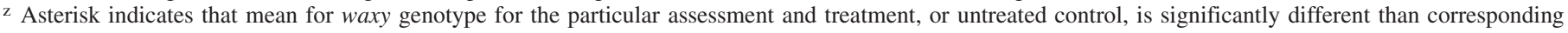
wild-type mean $(P \leq 0.05)$.

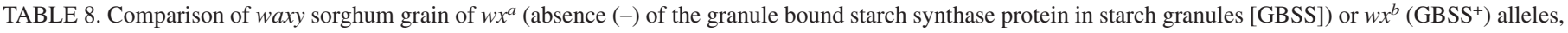

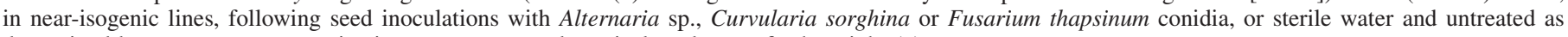
determined by mean percent germination, emergence and survival, and mean fresh weight $(\mathrm{g})^{\mathrm{y}}$

\begin{tabular}{|c|c|c|c|c|c|c|}
\hline \multirow[b]{2}{*}{ Assessment } & \multirow[b]{2}{*}{ Genotype } & \multicolumn{3}{|c|}{ Conidial treatments } & \multicolumn{2}{|c|}{ Controls } \\
\hline & & Alternaria $\mathrm{sp}$. & C. sorghina & F. thapsinum & Water & Untreated \\
\hline \multicolumn{7}{|c|}{ Near-isogenic line pairs } \\
\hline Germination & $w x^{a}$ & $88.7 \mathrm{a}^{\mathrm{z}} \pm 2.6$ & $88.4 \mathrm{a} \pm 2.6$ & $92.3 \mathrm{a} \pm 2.6$ & $89.4 a \pm 2.6$ & $89.1 \mathrm{a} \pm 2.6$ \\
\hline Emergence & $w x^{a}$ & $74.6 \mathrm{ab} \pm 11.6$ & $57.1 b \pm 13.4$ & $69.8 \mathrm{ab} \pm 11.6$ & $85.7 \mathrm{a} \pm 8.3$ & $84.1 \mathrm{a} \pm 8.5$ \\
\hline Survival & $w x^{a}$ & $66.7 \mathrm{ab} \pm 13.6$ & $52.4 \mathrm{~b} \pm 13.8$ & $55.6 \mathrm{~b} \pm 11.8$ & $84.1 \mathrm{a} \pm 11.4$ & $79.4 \mathrm{a} \pm 11.0$ \\
\hline Weight (g) & $w x^{a}$ & $0.30 \mathrm{~b} \pm 0.03$ & $0.17 \mathrm{c} \pm 0.03$ & $0.20 \mathrm{c} \pm 0.03$ & $0.37 \mathrm{ab} \pm 0.03$ & $0.41 \mathrm{a} \pm 0.03$ \\
\hline Germination & $w x^{b}$ & $91.7 \mathrm{a} \pm 1.7$ & $91.8 \mathrm{a} \pm 1.7$ & $90.3 \mathrm{a} \pm 1.7$ & $90.7 \mathrm{a} \pm 1.7$ & $92.1 \mathrm{a} \pm 1.7$ \\
\hline Emergence & $w x^{b}$ & $84.1 \mathrm{ab} \pm 11.6$ & $58.7 \mathrm{c} \pm 13.4$ & $65.1 b c \pm 11.6$ & $90.5 a \pm 8.3$ & $92.1 \mathrm{a} \pm 8.5$ \\
\hline Survival & $w x^{b}$ & $73.0 \mathrm{ab} \pm 13.6$ & $47.6 b \pm 13.9$ & $49.2 b \pm 11.8$ & $81.0 \mathrm{a} \pm 11.4$ & $90.5 \mathrm{a} \pm 11.0$ \\
\hline Weight (g) & $w x^{b}$ & $0.29 \mathrm{c} \pm 0.03$ & $0.14 \mathrm{~d} \pm 0.03$ & $0.19 \mathrm{~d} \pm 0.03$ & $0.32 b c \pm 0.03$ & $0.42 \mathrm{a} \pm 0.03$ \\
\hline
\end{tabular}

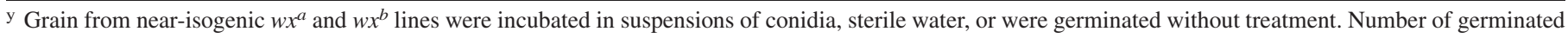
grains was determined. A subset of germinated grains was grown for three more weeks in soil at which time numbers of emerged plants and surviving plants were determined. Fresh weights were also determined and analyzed by total weights for a row and then divided by number of emergent plants in the row to determine mean weight per plant.

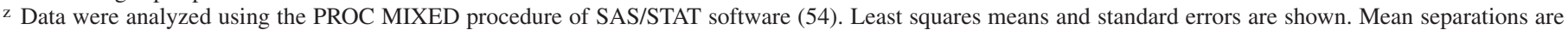
for response to four treatments or untreated, within a genotype and for a particular assessment. Means with different letters are significantly different at $P \leq 0.05$. 
comparable in stature to forage-type plants (50), but there were nine shorter, grain-height accessions. RCB design with single row plots was planted. A grain line was often planted beside taller plants, which could have affected light levels, day- and nighttime temperatures, air movement and relative humidity; changes in these conditions for infection, release and dispersal of airborne inoculum, and proximity to soil- or debris-borne inoculum, could have affected infection levels in shorter plants $(8,68)$. A previous study showed significant negative correlations between plant height and visual grain mold rating, demonstrating using QTL analyses that there were two genomic regions that affected both grain mold incidence and plant height or peduncle length (28). In the present study, there were no visible symptoms of grain mold, so grain was screened for internal, asymptomatic infection, yet a negative correlation between plant height and internal infection was still apparent (Table 4). The results of this and the previous studies may be relevant for intercropping sorghum with other crops (59) or possibly sorghum monoculture planted on sloped terrains with low areas or depressions $(30,40)$.

Grain from a subset of the accessions and $w x^{a}$ and $w x^{b}$ nearisogenic lines were challenged with conidia from an Alternaria isolate, and $C$. sorghina and $F$. thapsinum, previously isolated from grain sorghum $(16,17)$. These inoculation studies, which measured germination and seedling traits, supported the field results. There were incidences where all three fungal treatments had greater effects on waxy grain than on wild-type grain (Tables 6 and 7). However, there was no consistent and prevalent response that indicated that waxy lines were more susceptible to these grain pathogens than wild-type lines. This included near-isogenic $w x^{b}$ lines, indicating that through breeding at least some negative qualities associated with the $w x^{b}$ PI lines have been ameliorated (75). A direct comparison between waxy alleles $w x^{a}\left(\mathrm{GBSS}^{-}\right)$and $w x^{b}\left(\mathrm{GBSS}^{+}\right)$near-isogenic lines showed again no evidence that one allele was superior to the other (Table 8). Within individual lines, it was clear that inoculation with $C$. sorghina or F. thapsinum conidia could significantly reduce percent emergence and survival and fresh weight of inoculated seedlings (Tables 6, 7, and 8). In previous studies, maize kernels were inoculated with conidia of $F$. verticillioides and grown to maturity: a systemic infection occurred throughout entire plants and even infected kernels were produced on these plants $(41,42)$. In another study, kernels planted in F. verticillioides-infested soil were systemically infected as seedlings (47). In the present study, the results suggested that systemic fungal growth may be occurring, and this growth may be detrimental to survival or plant weight of sorghum seedlings. In a previous study, the grain produced from F. thapsinum-inoculated sorghum grain showed not to be infected with the pathogen (13). Thus, there is no evidence at this time that $F$. thapsinum continues to grow through the maturing plant, unlike the maize-F. verticillioides system (41). Even in this system where infected kernels were observed from plants systemically infected, in most cases fungal growth did not progress beyond plant crowns.

A beneficial consequence of this research was the identification of at least one new waxy allele among the waxy PIs. We wanted to ascertain that all the GBSS+ lines had the $w x^{b}$ allele and all GBSSlines had $w x^{a}$. Therefore, DNA from these waxy lines was subjected to marker analyses, previously published: all but one of the waxy alleles of the GBSS- lines were identified as containing the $w x^{a}$ allele, and two of the four $\mathrm{GBSS}^{+}$lines were identified as containing the $w x^{b}$ allele (Table 1). Two other $w x$ alleles had been recently identified in Asian germplasm collections, and based on the predicted amino acid sequences resulting from these mutations, both alleles produce the GBSS protein $(24,38)$. Therefore, the present study has discovered at least one and possibly as many as three novel waxy alleles. We are currently analyzing these potentially new waxy alleles.

In summary, this study used both field conditions and growth chamber inoculations of a diverse set of waxy and wild-type sorghum materials to demonstrate that the waxy trait does not increase susceptibility to common grain pathogens. Another benefit of this study was the finding of additional waxy alleles within existing accessions. The field study provided evidence that shorter plants may be more susceptible to fungal infection of their grain even if there are no visible symptoms. This study presented valuable results that could be utilized to choose waxy lines with resistance to grain-infecting fungi for hybrid seed production (Supplementary Tables 4 and 5).

\section{ACKNOWLEDGMENTS}

We thank J. Toy for overseeing field operations and producing greenhouse-grown grain; J. Toy and N. Palmer for valuable discussions; and K. Wohlgemuth, K. Drudik, and M. Sederberg for laboratory assistance. Funding was provided by the USDA-ARS, CRIS project 5440-21220-032-00D. Mention of trade names or commercial products in this article is solely for the purpose of providing specific information and does not imply recommendation or endorsement by the U.S. Department of Agriculture (USDA). USDA is an equal opportunity provider and employer.

\section{LITERATURE CITED}

1. Andrews, S., and Pitt, J. I. 1986. Selective medium for isolation of Fusarium species and dematiaceous hyphomycetes from cereals. Appl. Environ. Microbiol. 51:1235-1238.

2. Audilakshmi, S., Das, I. K., Ghorade, R. B., Mane, P. N., Kamatar, M. Y., Narayana, Y. D., and Seetharaman, N. 2011. Generic improvement of sorghum for grain mould resistance: I. Performance of sorghum recombinant inbred lines for grain mould reactions across environments. Crop Prot. 30:753-758.

3. Audilakshmi, S., Stenhouse, J. W., and Reddy, T. P. 2005. Genetic analysis of grain mold resistance in white seed sorghum genotypes. Euphytica 145: 95-101.

4. Bacon, C. W., Hinton, D. M., and Richardson, M. D. 1994. A corn seedling assay for resistance to Fusarium moniliforme. Plant Dis. 78:302-305.

5. Bandyopadhyay, R., Muchocho, L. K., and Satyanarayana, M. V. 1991. Occurrence of airborne spores of fungi causing grain mould over a sorghum crop. Mycol. Res. 95:1315-1320.

6. Barnett, H. L., and Hunter, B. B. 1972. Illustrated Genera of Imperfect Fungi, 3rd Ed. Burgess Publishing Co., Minneapolis, MN.

7. Brown, R. L., Cleveland, T. E., Payne, G. A., Woloshuk, C. P., Campbell, K. W., and White, D. G. 1995. Determination of resistance to aflatoxin production in maize kernels and detection of fungal colonization using an Aspergillus flavus transformant expressing Escherichia coli betaglucuronidase. Phytopathology 85:983-989.

8. Burdon, J. J., and Chilvers, G. A. 1982. Host density as a factor in plant disease ecology. Annu. Rev. Phytopathol. 20:143-166.

9. Chuck-Hernandez, C., Garcia-Lara, S., and Serna-Salvidar, S. O. 2012. Conversion into bioethanol of insect (Sitophilus zeamais Motschulsky), mold (Aspergillus flavus Link) and sprout-damaged maize (Zea mays L.) and sorghum (Sorghum bicolor L. Moench). J. Cereal Sci. 55:285-292.

10. Cruz, Y., Celis, L. P., Rooney, L. W., and McDonough, C. M. 1996. A ready-to-eat breakfast cereal from food-grade sorghum. Cereal Chem. 73: 108-114.

11. Damiran, D., and Yu, P. 2010. Chemical profile, rumen degradation kinetics, and energy value of four hull-less barley cultivars: Comparison of the zero-amylose waxy, waxy, high amylose, and normal starch cultivars. J. Agric. Food Chem. 58:10553-10559.

12. Fukunaga, K., Kawase, M., and Kato, K. 2002. Structural variation in the Waxy gene and differentiation in foxtail millet [Setaria italica (L. P. Beav.]: Implications for multiple origins of the waxy phenotype. Mol. Genet. Genomics 268:214-222.

13. Funnell-Harris, D. L., and Pedersen, J. F. 2008. Inoculation strategies to assess biological interactions between Fusarium and Alternaria species infecting sorghum. Can. J. Plant Pathol. 30:404-413.

14. Funnell-Harris, D. L., Pedersen, J. F., and Sattler, S. E. 2010. Alteration in lignin biosynthesis restricts growth of Fusarium spp. in brown midrib sorghum. Phytopathology 100:671-681.

15. Funnell-Harris, D. L., Pedersen, J. F., and Sattler, S. E. 2010. Soil and root populations of fluorescent Pseudomonas spp. associated with seedlings and field-grown plants are affected by sorghum genotype. Plant Soil 335: 439-455.

16. Funnell-Harris, D. L., Prom, L. K., and Pedersen, J. F. 2013. Isolation and characterization of the grain mold fungi, Cochliobolus and Alternaria spp., from sorghum using semi-selective media and DNA sequence analyses. Can. J. Microbiol. 59:87-96. 
17. Funnell-Harris, D. L., Prom, L. K., Sattler, S. E., and Pedersen, J. F. 2013. Response of near-isogenic lines, differing at the $P$ locus for plant colour, to grain mould and head smut fungi. Ann. Appl. Biol. 163:91-101.

18. Geiser, D. M., del Mar Jimenez-Gasco, M., Kang, S., Makalowska, I., Veeraraghavan, N., Wars, T. J., Zhang, N., Kuldau, G. A., and O’Donnell, K. 2004. FUSARIUM-ID v. 1.0: A DNA sequence database for identifying Fusarium. Eur. J. Plant Pathol. 110:473-479.

19. Graybosch, R. A. 1998. Waxy wheats: Origin, properties and prospects. Trends Food Sci. Technol. 9:135-142.

20. Graybosch, R. A., and Baltensperger, D. D. 2009. Evaluation of the waxy endosperm trait in proso millet (Panicum miliaceum). Plant Breed. 128: 70-73.

21. Hasjim, J., Srichuwong, S., Scott, M. P., and Jane, J.-L. 2009. Kernel composition, starch structure, and enzyme digestibility of opaque-2 maize and quality protein maize. J. Agric. Food Chem. 57:2049-2055.

22. Jambunathan, R., Kherdekar, M. S., and Stenhouse, J. W. 1992. Sorghum grain hardness and its relationship to mold susceptibility and mold resistance. J. Agric. Food Chem. 40:1403-1408.

23. Kang, H.-J., Hwang, I.-K., Kim, K.-S., and Choi, H.-C. 2006. Comparison of the physicochemical properties and ultrastructure of japonica and indica rice grains. J. Agric. Food Chem. 54:4833-4838.

24. Kawahigashi, H., Oshima, M., Nishikawa, T., Okuiziumi, H., Kasuga, S., and Yonemaru, J.-I. 2013. A novel waxy allele in sorghum landraces in East Asia. Plant Breed. 132:305-310.

25. Kenward, M. G., and Roger, J. H. 1997. Small sample inference for fixed effects from restricted maximum likelihood. Biometrics 53:983-997.

26. Khullar, E., Sall, E. D., Rausch, K. D., Tumbleson, M. E., and Singh, V. 2009. Ethanol production from modified and conventional dry-grind processes using different corn types. Cereal Chem. 86:616-622.

27. King, A. D., Jr., Hocking, A. D., and Pitt, J. I. 1979. Dichloran-rose bengal medium for enumeration and isolation of molds from foods. Appl. Environ. Microbiol. 37:959-964.

28. Klein, R. R., Rodriguez-Herrera, R., Schlueter, J. A., Klein, P. E., Yu, Z. H., and Rooney, W. L. 2001. Identification of genomic region that affect grain-mould incidence and other traits of agronomic importance in sorghum. Theor. Appl. Genet. 102:307-319.

29. Kumari, S. R., and Chandrashekar, A. 1992. Proteins in developing sorghum endosperm that may be involved in resistance to grain moulds. J. Sci. Food Agric. 60:275-282.

30. Kutcher, H. R., Malhi, S. S., and Gill, K. S. 2005. Slope position, nitrogen fertilizer, and fungicide effects on diseases and productivity of wheat on a hummocky landscape. Agron. J. 97:1452-1459.

31. Lee, S. B., and Taylor, J. W. 1990. Isolation of DNA from fungal mycelia and single spores. Pages 282-287 in: PCR Protocols: A Guide to Methods and Applications. M. A. Innis, D. H. Gelfand, J. J. Sninsky, and T. J. White, eds. Academic Press, Inc., San Diego, CA.

32. Leslie, J. F., and Summerell, B. A. 2006. The Fusarium Laboratory Manual. Blackwell Publishing, Ames, IA

33. Leslie, J. F., Zeller, K. A., Lamprecht, S. C., Rheeder, J. P., and Marasas, W. F. O. 2005. Toxicity, pathogenicity, and genetic differentiation of five species of Fusarium from sorghum and millet. Phytopathology 95:275-283.

34. Lichtenwalner, R. E., Ellis, E. B., and Rooney, L. W. 1978. Effect of incremental dosages of the waxy gene of sorghum on digestibility. J. Anim. Sci. 46:1113-1119.

35. Lillehoj, E. B., Zaber, M. S., Darrah, L. L., Kwolek, W. F., Findley, W. R., Horner, E. S., Scott, G. E., Manwiller, A., Sauer, D. B., Thompson, D., Warren, H., West, D. R., and Widstrom, N. W. 1983. Aflatoxin occurrence and levels in preharvest corn kernels with varied endosperm characteristics grown at diverse locations. Crop Sci. 23:1181-1184.

36. Lincy, S. V., Chandrashekar, A., Narayan, M. S., Sharma, R., and Thakur, R. P. 2011. Natural occurence of trichothecene-producing Fusaria isolated from India with particular reference to sorghum. World J. Microbiol. Biotechnol. 27:981-989.

37. Loesch, P. J., Foley, D. C., and Cox, D. F. 1976. Comparative resistance of opaque-2 and normal inbred lines of maize to ear-rotting pathogens. Crop Sci. 16:841-842

38. Lu, Y., Zhao, G., Li, Y., Fan, J., Ding, G., Zhao, J., Ni, X., Xy, Y., and Wang, W. 2013. Identification of two novel waxy alleles and development of their molecular markers in sorghum. Genome 56:283-288.

39. Menkir, A., Ejeta, G., Butler, L. G., Melakeberhan, A., and Warren, H. L. 1996. Fungal invasion of kernels and grain mold damage assessment in diverse sorghum germplasm. Plant Dis. 80:1399-1402.

40. Muller, M. E. H., Koszinski, S., Brenning, A., Verch, G., Korn, U., and Sommer, M. 2011. Within-field variation of mycotoxin contamination of winter wheat is related to indicators of soil moisture. Plant Soil 342: 289-300.

41. Munkvold, G. P., and Carlton, W. M. 1997. Influence of inoculation method on systemic Fusarium moniliforme infection of maize plants grown from infected seeds. Plant Dis. 81:211-216.
42. Murillo-Williams, A., and Munkvold, G. P. 2008. Systemic infection by Fusarium verticillioides in maize plants grown under three temperature regimes. Plant Dis. 92:1695-1700.

43. Nash, S. M., and Snyder, W. C. 1962. Quantitative estimations by plate counts of propagules of the bean root rot Fusarium in field soils. Phytopathology 52:567-572.

44. Navi, S. S., Bandyopadhyay, R., Reddy, R. K., Thakur, R. P., and Yang, X. B. 2005. Effects of wetness duration and grain development stages on sorghum grain mold infection. Plant Dis. 89:872-878.

45. Nelson, P. E., Toussoun, T. A., and Marasas, W. F. O. 1983. Fusarium Species: An Illustrated Manual for Identification. The Pennsylvania State University Press, University Park.

46. Ni, D., Zhang, X., Chen, S., Xu, Y., Li, L., Li, H., Wang, Z., Cai, X., Li, Z., and Yang, J. 2011. Improving cooking and eating quality of Xieyou57, and elite indica hybrid rice, by marker-assisted selection of the $W x$ locus. Euphytica 179:355-362.

47. Oren, L., Ezrati, S., Cohen, D., and Sharon, A. 2003. Early events in the Fusarium verticillioides-maize interaction characterized by using a green fluorescent protein-expressing transgenic lines. Appl. Environ. Microbiol. 69:1695-1701.

48. Pedersen, J. F., Bean, S. R., Funnell, D. L., and Graybosch, R. A. 2004. Rapid iodine staining techniques for identifying the waxy phenotype in sorghum grain and waxy genotype in sorghum pollen. Crop Sci. 44:764-767.

49. Pedersen, J. F., Bean, S. R., Graybosch, R. A., Park, S. H., and Tilley, M. 2005. Characterization of waxy grain sorghum lines in relation to granulebound starch synthase. Euphytica 144:151-156.

50. Pedersen, J. F., Graybosch, R. A., and Funnell, D. L. 2007. Occurrence of the waxy alleles $w x^{a}$ and $w x^{b}$ in waxy sorghum plant introductions and their effect on starch thermal properties. Crop Sci. 47:1927-1933.

51. Prom, L. K., Waniska, R. D., Kollo, A. I., Rooney, W. L., and Bejosano, F. P. 2005. Role of chitinase and sormatin accumulation in the resistance of sorghum cultivars to grain mold. J. Agric. Food Chem. 53:5565-5570.

52. Rodriguez-Herrera, R., Waniska, R. D., Rooney, W. L., Aguilar, C. N., and Contreras-Esquivel, J. C. 2006. Antifungal proteins during sorghum grain development and grain mould resistance. J. Phytopathol. 154:565-571.

53. Sang, Y., Bean, S., Seib, P. A., Pedersen, J., and Shi, Y.-C. 2008. Structure and functional properties of sorghum starches differing in amylose content. J. Agric. Food Chem. 56:6680-6685.

54. SAS. 2002-2008. The data analysis for this paper was generated using SAS/STAT software, Version 9.2 of the SAS System for Windows. SAS Institute Inc., Cary, NC.

55. Sattler, S. E., Cahoon, E. B., Coughlan, S. J., and DellaPenna, D. 2003. Characterization of tocopherol cyclases from higher plants and cyanobacteria. Evolutionary implications for tocopherol synthesis and function. Plant Physiol. 132:2184-2195

56. Sattler, S. E., Singh, J., Haas, E. J., Guo, L., Sarath, G., and Pedersen, J. F. 2009. Two distinct waxy alleles impact the granule-bound starch synthase in sorghum. Mol. Breed. 24:349-359.

57. Saubois, A., Piontelli Laforet, E., Nepote, M. C., and Wagner, M. L. 1999. Mycological evaluation of a sorghum grain of Argentina, with emphasis on the characterization of Fusarium species. Food Microbiol. 16:435-445.

58. Sauer, D. B., Seitz, L. M., Burroughs, R., Mohr, H. E., West, J. L., Milleret, R. J., and Anthony, H. D. 1978. Toxicity of Alternaria metabolites found in weathered sorghum grain at harvest. J. Agric. Food Chem. 26:1380-1383.

59. Schittenhelm, S. 2010. Effect of drought stress on yield and quality of maize/sunflower and maize/sorghum intercrops for biogas production. J. Agron. Crop Sci. 196:253-261.

60. Schmidt, R. J., Burr, F. A., Aukerman, M. J., and Burr, B. 1990. Maize regulatory gene opaque-2 encodes a protein with a "leucine-zipper" motif that binds to zein DNA. Proc. Natl. Acad. Sci. USA 87:46-50.

61. Seetharaman, K., Waniska, R. D., and Rooney, L. W. 1996. Physiological changes in sorghum antifungal proteins. J. Agric. Food Chem. 44: 2435-2441.

62. Seetharaman, K., Whitehead, E., Keller, N. P., Waniska, R. D., and Rooney, L. W. 1997. In vitro activity of sorghum seed antifungal proteins against grain mold pathogens. J. Agric. Food Chem. 45:3666-3671.

63. Sharma, R., Rao, V. P., Upadhyaya, H. D., Gopal Reddy, V., and Thakur, R. P. 2010. Resistance to grain mold and downy mildew in a mini-core collection of sorghum germplasm. Plant Dis. 94:439-444.

64. Sherrod, L. B., Albin, R. C., and Furr, R. D. 1969. Net energy of regular and waxy sorghum grains for finishing steers. J. Anim. Sci. 29:997-1000.

65. Shure, M., Wessler, S., and Federoff, N. 1983. Molecular identification and isolation of the Waxy locus in maize. Cell 35:225-233.

66. Simmons, E. G. 1999. Alternaria themes and variations (226-235): Classification of citrus pathogens. Mycotaxon 70:263-323.

67. Smith, C. W., and Frederiksen, R. A. 2000. Sorghum: Origin, History, Technology and Production. Page 824 in: Wiley Series in Crop Science. C. W. Smith, ed. John Wiley and Sons, Inc., New York. 
68. Subba Reddi, C., and Ramakrishna, V. 1978. Vertical profiles of spore concentration within and above a Sorghum crop. Phytopathol. Z. 93:35-40.

69. Tarekegn, G., McLaren, N. W., and Swart, W. J. 2006. Effects of weather variables on grain mould of sorghum in South Africa. Plant Pathol. 55: 238-245.

70. Tropics, I. I. C. R. I. S.-A. 1980. Proceedings of the International Workshop on Sorghum Diseases, sponsored jointly by Texas A\&M University, USA, and ICRISAT, Hyberabad, India.

71. Williams, R. J., and Rao, K. N. 1980. A review of sorghum grain mold. Pages 79-92 in: Proceedings of the International Workshop of Sorghum Diseases. R. J. Williams, R. A. Frederiksen, and L. K. Mughogho, eds. ICRISAT, Andhra Pradesh, India.

72. Wong, J. H., Lau, T., Cai, N., Singh, J., Pedersen, J. F., Vensel, W. H., Hurkmen, W. J., Wilson, J. D., Lemaux, P. G., and Buchanan, B. B. 2009. Digestibility of protein and starch from sorghum (Sorghum bicolor) is linked to biochemical and structural features of grain endosperm. J. Cereal Sci. 49:73-82.

73. Wu, X., Jampala, B., Robbins, A., Hays, D., Yan, S., Xy, F., Rooney, W., Peterson, G., Shi, Y.-C., and Wang, D. 2010. Ethanol fermentation performance of grain sorghums (Sorghum bicolor) with modified endosperm matrices. J. Agric. Food Chem. 58:9556-9562.

74. Wu, X., Zhao, R., Bean, S. R., Seib, P. A., McLaren, J. S., Madl, R. L., Tuinstra, M., Lenz, M. C., and Wang, D. 2007. Factors impacting ethanol production from grain sorghum in the dry-grind process. Cereal Chem. 84:130-136.

75. Yerka, M. K., Toy, J. J., Funnell-Harris, D. L., Sattler, S. E., and Pedersen, J. F. 2015. Registration of N619 to N640 grain sorghum lines with waxy or wild-type endosperm. J. Plant Reg. 9:249-253.

76. Zhao, R., Wu, X., Seabourn, W., Bean, S. R., Guan, L., Shi, Y.-C., Wilson, J. D., Madl, R., and Wang, D. 2009. Comparison of waxy vs. nonwaxy wheats in fuel ethanol fermentation. Cereal Chem. 86:145-156. 